\title{
CARLOS NINO Y LA TITULARIDAD DEL DERECHO A UN AMBIENTE SANO
}

\author{
María Florencia SaUlino* \\ Universidad de Palermo
}

\section{Resumen}

La mayoría de los derechos reconocidos tanto a nivel constitucional como en el derecho internacional de los derechos humanos están destinados a la protección de bienes privados. A diferencia de ellos, el derecho al ambiente sano asegura a los individuos el disfrute de un bien público. Las características propias de los bienes públicos generan profundos problemas de arquitectura jurídica para un sistema de derechos fundamentales que históricamente fue concebido para la protección de bienes privados y han dado lugar a discusiones sobre la titularidad de este derecho. Este trabajo analiza la posición de Carlos S. Nino a favor de considerar el derecho a un ambiente sano como derecho colectivo y señala los problemas que esta postura genera para el ejercicio y contenido del derecho.

PALABRAS CLAVE: Derechos colectivos; Derechos individuales; Derecho al ambiente sano; Titularidad.

\begin{abstract}
Most of the rights that have been recognized both at the constitutional level and in international human rights laws entitle individuals to the protection of private goods. In contrast, the right to a healthy environment ensures individuals the enjoyment of a public good. The characteristics of public goods have created significant problems related to the legal architecture for a system of fundamental rights that historically was conceived for the protection of private goods, and have generated considerable debate over whether the right to a healthy environment should be considered an individual right. This paper analyzes Carlos S. Nino's position, who advocates in favor of considering the right to a healthy environment as a collective right; and it points out the problems that such a position generates for the content of the right and its exercise.
\end{abstract}

KEY WORDS: Collective Rights; Individual Rights; Right to a Healthy Environment; Right holder.

* Este trabajo forma parte de mi tesis para el doctorado en Derecho de la Universidad de Buenos Aires y se publica con la autorización de mi director, el Dr. Marcelo Alegre. Quisiera agradecer especialmente a Marcelo Alegre, Martín Böhmer, Martín Farrell y Joaquín Millón por los comentarios a las primeras versiones del trabajo. 


\section{Introducción}

La mayoría de los derechos reconocidos tanto a nivel constitucional como en el derecho internacional de los derechos humanos están destinados a la protección de bienes privados -como la vida, la libertad, la seguridad personal y la propiedad-o a garantizar el acceso a este tipo de bienes por parte de toda la población -como el derecho a la salud o a la educación (Brunnée 1989, p. 798; Green 1991, p. 317; Desai 2003, p. 63). ${ }^{1}$ A diferencia de ellos, el derecho al ambiente sano asegura a los individuos el disfrute de un bien público.

Los bienes públicos se diferencian de los bienes privados en que, una vez que existen, todos los miembros del grupo pueden disfrutar del bien, sin que el disfrute por parte de un individuo afecte la oportunidad de los demás de disfrutarlo (no rivalidad), y sin que ninguno de los miembros del grupo pueda ser excluido de su goce (imposibilidad de exclusión) (Cornes y Sandler 1986, p. 6). Estas características generan profundos problemas de arquitectura jurídica para un sistema de derechos fundamentales que históricamente fue concebido para la protección de bienes privados.

En términos de las categorías propuestas por Hohfeld (1913, p. 36), el derecho a un ambiente sano sería fundamentalmente un derechopretensión. Decir que X tiene un derecho a un ambiente sano G, implica que el Estado tiene un deber correlativo de hacer todo lo posible para que $\mathrm{X}$ tenga G; y que todo el resto de los individuos tienen un deber de no realizar acciones que impidan que $\mathrm{X}$ tenga $\mathrm{G}$. Asimismo, el derecho a un ambiente sano, cuando es reconocido a nivel constitucional, incluye una inmunidad que impide que otros individuos o el propio Estado alteren la posición legal de $\mathrm{X}$ con respecto a $\mathrm{G}$.

Sin embargo, dado que $\mathrm{G}$ es un bien público, no es posible sostener que el derecho a $\mathrm{G}$ implica una potestad que le permite a $\mathrm{X}$ alterar las relaciones jurídicas existentes respecto de G. En efecto, la imposibilidad de exclusión, propia de los bienes públicos, lleva a que si $\mathrm{G}$ es un bien público para $\mathrm{X}_{1}, \mathrm{X}_{2}, \mathrm{y} \mathrm{X}_{3}$, una vez que $\mathrm{G}$ existe, $\mathrm{X}_{1}, \mathrm{X}_{2} \mathrm{y}_{3}$ reciben $\mathrm{G}$, sin que ninguno de ellos pueda ser excluido (o excluirse) de su goce. Por tanto, una vez que $\mathrm{X}_{1}$ reclama la provisión de $\mathrm{G}, \mathrm{G}$ se provee a todo $\mathrm{X}$, sin que $\mathrm{X}_{2} \mathrm{y}_{3}$ puedan decidir no recibir $\mathrm{G}$, negociar una compensación por la falta de G, o eximir al Estado de su deber de proveer G, o a otro ciudadano

1 "Tradicionalmente los derechos humanos se le otorgan a los individuos para la protección de 'bienes privados' como la vida, el bienestar o la propiedad. Sin embargo, los recursos naturales como el agua o el aire son 'bienes públicos"' (Brunnée 1989, p. 798). Las traducciones de textos ingleses que aparecen en este artículo son de mi autoría. 
de su deber de no interferir con la provisión de G. En efecto, tales transacciones carecerían de sentido, ya que aun cuando $\mathrm{X}_{2}$ llegara a un acuerdo con el Estado o directamente renunciara a acceder a G, la demanda de cualquier otro $X$ de que $G$ se provea beneficiaría automáticamente a $\mathrm{X}_{2}$ que no podría ser excluido de su goce.

Estas características del derecho al ambiente sano han generado discusiones sobre la titularidad del derecho reconocido en el Art. 41 de nuestra Constitución Nacional. En efecto, algunos autores considera que el derecho al ambiente sano debe entenderse como un derecho colectivo (Badeni 1997, p. 310; Lorenzetti 2008, p. 35), mientras que otros se inclinan por considerarlo un derecho individual, aunque reconociendo sus particularidades (Bidart Campos 2002, p. 98; Tawil 1995; Esaín, Minella y Jiménez 2010, p. 1003).

Carlos Nino fue quizás uno de los primeros autores en abordar el problema de la titularidad del derecho al ambiente sano, aun antes de que la reforma de 1994 reconociera explícitamente este derecho. En efecto, en su libro Fundamentos de derecho constitucional, Nino se refiere especialmente a la necesidad de incluir derechos ambientales en una eventual reforma de la Constitución, ya que el medio ambiente forma parte de lo que "constituye una vida valiosa de acuerdo con muchos ideales personales" (1992, p. 351). Si bien Nino pareciera aceptar la posibilidad de que existan sobre los bienes públicos tanto derechos individuales como derechos colectivos, en Fundamentos de derecho constitucional aboga por el reconocimiento de un derecho colectivo al medio ambiente sano. ${ }^{2}$

Este trabajo busca analizar la posición de Nino sobre la titularidad del derecho a un ambiente sano. Para ello, la sección 2 presenta la definición de derecho colectivo propuesta por Joseph Raz que ha sido tomada como base para el análisis de Nino. La sección 3 expone las críticas de Nino a la definición de Raz y su propuesta de considerar al derecho al ambiente sano como un derecho colectivo. La sección 4 analiza las consecuencias que se desprenden de esta posición. Argumentaré que considerar el derecho al ambiente sano como un derecho colectivo no solo no soluciona los problemas de arquitectura legal a los que me he referido, sino que también genera nuevos problemas relacionados con el ejercicio y contenido del derecho. Finalmente, la sección 5 concluye señalando que si bien el derecho al ambiente sano tiene características que lo diferencian de los derechos tradicionales, su inclusión en la categoría de los derechos individuales resulta preferible.

2 "Creo que la idea de derechos colectivos es particularmente útil para encarar problemas como el del medio ambiente" (Nino 1992, p. 351). 


\section{Raz y los derechos sobre bienes públicos}

Si bien Raz solo aborda el tema de los derechos sobre bienes públicos como parte de su crítica a las teorías morales basadas en derechos, numerosos autores ${ }^{3}$-entre ellos Carlos Nino- toman su análisis como base para la discusión de este tipo de derechos, por lo que resulta conveniente comenzar por revisar su teoría (Raz 1984). Para su análisis, Raz propone una subclasificación de los bienes públicos en bienes inherentemente públicos -a los que llama "bienes colectivos"- y bienes públicos contingentes. Los bienes inherentemente públicos son bienes de cuyo goce es lógicamente imposible excluir a alguien, mientras que en el caso de los bienes públicos contingentes tal exclusión es lógicamente posible pero, como consecuencia de una "contingencia" -que puede ser la falta de una tecnología adecuada para hacerlo- en la práctica se torna imposible excluir a alguien de su goce:

Las características generales beneficiosas de la sociedad son bienes inherentemente públicos [...] Diferentes personas se benefician de las buenas cualidades de la sociedad en diferentes grados. Pero el grado en que se benefician depende de su caracter, intereses y predisposiciones, y no puede ser controlada directamente por los demás [...] Naturalmente uno puede excluir a los individuos del beneficio de dichos bienes excluyéndolos de la sociedad a la que pertenecen. Pero eso no afecta su carácter de bienes públicos que depende de la no exclusividad de su disfrute entre los miembros de la sociedad para la que son bienes públicos. Voy a llamar a los bienes inherentemente públicos "bienes colectivos" (Raz 1984, p. 187).

Según la definición de Raz, el ambiente sano constituiría un bien inherentemente público (o bien colectivo) ya que no es posible pensar en una tecnología existente o futura que nos permita convertirlo en un bien privado. Si bien Raz no niega la posibilidad de que existan derechos individuales sobre bienes públicos contingentes, señala que, en lo que respecta a los bienes inherentemente públicos, estos derechos son difíciles de sostener:

El mantenimiento de un bien colectivo afecta la vida e impone restricciones en las actividades de una gran parte de la población, en

${ }^{3}$ Las categorías propuestas por Raz han sido utilizadas, entre otros, por Réaume (1988), Green (1991), Waldron (1993), Newman (2004) y Jovanovi (2012). 
asuntos que los afectan profundamente. Es difícil imaginar un argumento exitoso para imponer el deber de proveer un bien público sobre la base de que este serviría los intereses de [solamente] un individuo (Raz 1986, p. 209).

En consecuencia, para Raz este tipo de bienes solo podría ser objeto de derechos colectivos. En efecto, Raz define a los derechos colectivos como derechos destinados a la protección de aquellos bienes públicos que sirven a los intereses de los individuos como miembros de la comunidad a la que pertenecen:

Existe un derecho colectivo cuando se cumplen las siguientes tres condiciones: primero, existe porque los intereses de los seres humanos justifican que alguna(s) persona(s) este(n) sujetas a un deber. Segunda, los intereses en cuestión son los intereses de los individuos como miembros del grupo en un bien público y el derecho es un derecho a ese bien público porque sirve sus intereses como miembros del grupo. Tercero, el interés de ningún miembro individual de ese grupo en ese bien público es suficiente por sí mismo para justificar que otra persona esté sujeta a un deber (Raz 1984, p. 194).

Raz explica que la primera de las condiciones es necesaria para que los derechos colectivos sean consistentes con el humanismo. ${ }^{4}$ En este sentido, los derechos colectivos solo pueden existir si sirven a los intereses de los individuos, y los intereses colectivos son solo una forma de referirse a los intereses individuales que surgen como consecuencia de la pertenencia del individuo a una comunidad. ${ }^{5}$ La segunda y tercera condición son las que distinguen al derecho colectivo de un mero conjunto de derechos individuales ( $\operatorname{Raz} 1984$, p. 194).

Raz ejemplifica su definición utilizando el derecho a la autodeterminación: (i) el valor de este derecho radica en que la autodeterminación contribuye al bienestar de los miembros individuales de las minorías oprimidas como miembros del grupo; (ii) la autodeterminación es un bien colectivo y el interés de los individuos en este bien surge como consecuencia de su pertenencia al grupo; y (iii) si

${ }^{4}$ Para Raz, el humanismo establece una condición necesaria para la aceptabilidad de las teorías morales (Raz 1984, p. 183, 1986, p. 194).

5 "Los intereses colectivos son una mera forma de hablar. Son una forma de referirse a los intereses individuales que surgen de la membresía de los individuos en las comunidades" (Raz 1986, p. 208). 
bien muchos de los miembros individuales del grupo tienen un interés en la autodeterminación de su comunidad, el interés individual de cualquiera de ellos es un fundamento insuficiente para generar en otros la obligación de satisfacer ese interés (Raz 1984, p. 194). En efecto, sería imposible obligar a toda una comunidad a autodeterminarse con el argumento de que esto serviría al interés de un individuo. Por tanto, para Raz, el derecho a la autodeterminación pertenece a toda la comunidad, a la vez que no es posible sostener la existencia de un derecho individual a que la comunidad se autodetermine (Raz 1984, p. 193).

Al proponer su definición, Raz pareciera tener en mente un solo tipo de derechos colectivos: aquellos que tienen por titulares a grupos minoritarios dentro de la sociedad. ${ }^{6}$ En efecto, si bien la definición de Raz no requiere ninguna característica específica del grupo en cuestión para que este pueda ser considerado como titular del derecho, al hablar de los intereses del individuo lo hace en términos de los intereses que el individuo tiene "como miembros del grupo" (Raz 1984, p. 194). Asimismo, en The Morality of Freedom, al analizar el ejemplo de Yassir Arafat y la autodeterminación de Palestina, Raz explica que el interés de Yassir Arafat en la autodeterminación de su pueblo se basa, al menos en parte, en su interés en vivir en una comunidad que le permita expresar sin represión aquellos aspectos de su personalidad que están conectados a su sentido de identidad como miembro de su comunidad (Raz 1986, p. 207).

Es decir, que los derechos colectivos contemplados en la definición de Raz estarían restringidos a aquellos grupos que tienen características distintivas dentro de la sociedad, más allá de compartir un interés en común. ${ }^{7}$ Esto se verifica en el caso del derecho a la autodeterminación, al mantenimiento de la cultura, los derechos de comunidades religiosas o el derecho a la lengua. Sin embargo, este razonamiento no es trasladable

\footnotetext{
${ }^{6}$ Muchos autores definen el término "derechos colectivos" como los derechos de las colectividades o grupos minoritarios frente al resto de la sociedad: "Los derechos colectivos se refieren a la protección de algunas características del grupo, que distinguen al grupo como un todo de otros pueblos" (Galenkamp 1991).

7 "Es difícil ver cómo Raz puede ser seriamente entendido de cualquier otra forma que como restringiendo el alcance de los derechos colectivos a aquellos grupos con características distintivas más allá de su interés compartido" (Jovanovi 2012, p. 104). Por el contrario, Jones sostiene que "Raz utiliza frases tales como 'miembros de un grupo' en su definición de derecho colectivo pero yo lo tomo como refiriéndose a la membresía en un grupo identificado por su interés compartido en el bien público en cuestión. No puedo concebir cómo, dada su concepción general de los derechos, Raz podría justificadamente restringir los derechos colectivos a grupos que se distinguen como tales por alguna característica que es independiente de los intereses que justifican sus derechos" (Jones 1999).
} 
al derecho a un ambiente sano. En efecto, en el caso del derecho al ambiente sano el individuo tiene un interés en vivir en un ambiente de dichas características, independientemente de su pertenencia o no a un grupo determinado.

La tercera condición de Raz es que el interés de ningún miembro individual del grupo sea suficiente en sí mismo para justificar la imposición de un deber en otra persona. Raz explica que los individuos no podrían tener un derecho individual a un bien inherentemente público ya que "[e]s difícil imaginar un argumento exitoso para imponer el deber de proveer un bien público sobre la base de que este serviría los intereses de un individuo". Al analizar el ejemplo de Yassir Arafat y la autodeterminación Palestina, Raz señala que Arafat no podría tener un derecho individual a la autodeterminación de Palestina puesto que la satisfacción de dicho derecho "impone amplias demandas a la vida de toda la comunidad. El interés de Arafat en sí mismo no justifica imponer tan amplios deberes a tantas otras personas" (Raz 1986, pp. 187, 209).

Sin embargo, en su análisis Raz no explica por qué la imposibilidad de exclusión absoluta -que es la característica que utiliza para definir a este tipo de bienes- haría que resulte difícil imponer el deber de proveer un bien inherentemente público para satisfacer el interés de un solo individuo. ${ }^{8} \mathrm{El}$ costo que implica la provisión de estos bienes no parece ser razón suficiente para sostener que solo el interés agregado de un grupo de individuos puede fundar el deber de proveerlos, especialmente si tenemos en cuenta el costo que impone a la sociedad la provisión de otros bienes que típicamente son objeto de derechos individuales. ${ }^{9}$

${ }^{8}$ Para Newman "el derecho a los bienes colectivos de Raz es no individualizable (dependiendo no solo del interés de un individuo) porque ningún interés individual por sí mismo tiene un peso suficiente para justificar el derecho. Pero es solo una mera conjetura que ningún interés individual por sí mismo tenga un peso suficiente para justificar el bien. De hecho, podríamos fácilmente conjeturar que algunos intereses individuales tienen un peso suficiente para justificar los bienes colectivos de Raz" (Newman 2004, p. 153).

${ }^{9}$ En este sentido, Waldron señala que " $[\mathrm{m}]$ uchos bienes privados son muy costosos de producir y mantener. Y estamos seguros de que las personas tienen derechos a muchas cosas (como la libertad de asociación política, por ejemplo) que pueden imponer costos inmensos en el gobierno y, por tanto, indirectamente en la masa de nuestros conciudadanos. Dado que, sin embargo, creemos que algunas veces las personas tienen derechos a dichos bienes, el mero hecho de que el costo de proveer un bien 'colectivo' sea oneroso y generalizado no puede ser una razón para negar que son un objeto plausible para los derechos" (Waldron 1993, p. 350). Para una crítica a la posición de Raz y un argumento en favor de la existencia de derechos individuales sobre bienes públicos pueden verse los trabajos de Réaume (1988) y Waldron (1993). 
Parecería, entonces, que para Raz no es posible concebir el derecho al ambiente sano como un derecho individual -ya que tiene por objeto a un bien "inherentemente público"- ni tampoco como un derecho colectivo -ya que el bien no sirve a los intereses del individuo "como miembro del grupo".

\section{La posición de Nino}

Nino critica el razonamiento de Raz que llevaría a sostener que sobre el ambiente sano no podrían existir ni derechos individuales ni derechos colectivos. ${ }^{10}$ En Ética y derechos humanos destaca que "no parece conceptualmente objetable que haya derechos individuales a bienes colectivos" (1989, p. 226). En este sentido, señala que la objeción de Raz se basa en que no existe el deber de proveer tales bienes. Sin embargo, para Nino $(1989,1992)$, los derechos individuales no requieren que exista el deber o la obligación de proveer los bienes que son contenido de los derechos, sino tan solo que el acceso a tales bienes sea moralmente debido o correcto.

Por otra parte, en Fundamentos de derecho constitucional destaca que tampoco surge con claridad del razonamiento de Raz por qué no podría haber derechos colectivos que no dependan de la pertenencia a un grupo en especial: "[p]recisamente uno está tentado a decir que cualquier persona tiene derecho a un medio ambiente saludable, independientemente del grupo al que pertenezca" (Nino 1992, pp. 350-351).

Es decir que, si bien Nino pareciera aceptar la posibilidad de que existan sobre los bienes públicos tanto derechos individuales como derechos colectivos, aboga por el reconocimiento de un derecho colectivo al medio ambiente sano. En efecto, en Fundamentos señala que "la idea de derechos colectivos es particularmente útil para encarar problemas como el del medio ambiente" (1992 p. 351). El derecho al ambiente sano sería entonces, para Nino, un derecho colectivo que no depende de la pertenencia a un grupo con características distintivas, sino que bastaría con que el conjunto de individuos comparta un interés en la existencia de dicho bien público. Como se mostrará en las siguientes secciones, esta postura no está exenta de problemas.

10 Para Nino, la argumentación de Raz "tiene varios pasos discutibles que hacen dudar de la conclusión en contra de la existencia de derechos a bienes colectivos" (Nino 1992, p. 350). 


\section{El derecho al ambiente sano como derecho colectivo}

El término "derecho colectivo" ha sido utilizado para referirse a dos tipos muy distintos de derechos: (i) los derechos que pertenecen a las comunidades de forma independiente y separada de sus miembros ("derechos de grupo"); y (ii) los derechos que se le reconocen a los individuos por su pertenencia a una determinada comunidad ("derechos especiales"). Kymlicka señala que los derechos de grupo tienen como titular a la comunidad, existen a la par de los derechos individuales y pueden incluso entrar en conflicto con los derechos de los miembros que integran el grupo (1994, pp. 18-20). En cambio, los derechos especiales son derechos que se le reconocen a los miembros de una determinada comunidad -los quebequenses, las tribus indígenas, las comunidades etnoculturales- de forma tal de asegurar que la sociedad no los prive de las condiciones necesarias para su existencia (Kymlicka 1994, p. 20). ${ }^{11} \mathrm{El}$ titular de este último tipo de derechos puede ser tanto la comunidad-como por ejemplo los derechos de caza que se le reconocen a ciertas tribus-como el individuo -así, por ejemplo, el derecho de los quebequenses a utilizar el idioma francés en los tribunales- (Kymlicka 1994, p. 23). A diferencia de los derechos de grupo, los derechos especiales solo pueden existir en sociedades plurales, ya que su objetivo es proteger a determinada cultura de las influencias desestabilizadoras de la sociedad como un todo (Kymlicka 1994, p. 19).

El derecho a un ambiente sano como derecho colectivo solo podría ser incluido dentro de la primera de estas categorías, ya que no es posible concebirlo como un derecho limitado a los miembros de determinadas comunidades como forma de mantener sus tradiciones dentro de una sociedad multicultural.

Sin embargo, no es posible equiparar sin más a los grupos -que serían titulares de los derechos colectivos- con los individuos -que históricamente han sido los titulares de los derechos fundamentales-. En este sentido, Waldron señala que es suficiente con observar el intrincado cuerpo normativo que hemos desarrollado para regir la vida de las personas

11 Este tipo de derechos incluyen "la representación de la comunidad minoritaria en las instituciones políticas de la sociedad (como, por ejemplo, la representación de miembros de la minoría francoparlante en la Corte Suprema de Canadá), la devolución de poderes a la comunidad minoritaria (como la jurisdicción sobre la inmigración que se le otorga a Quebec), o la protección directa de los recursos o prácticas de los que depende la comunidad minoritaria (por ejemplo los derechos de la minoría a la lengua o los derechos de los pueblos originarios a la caza o las tierras que tradicionalmente ocupan)” (Kymlicka 1994, p. 20). 
jurídicas, para darnos una idea las dificultades que presentan este tipo de derechos (2002, p. 209). Por tanto, antes de poder incluir el derecho a un ambiente sano dentro de la categoría de los derechos de grupo, es necesario examinar al menos tres problemas asociados a este tipo de derechos: (i) quién sería el titular; (ii) cuál sería el contenido del derecho y (iii) quién puede ejercerlo en nombre del colectivo (Merrills 1996, pp. 31-32).

\subsection{Titularidad}

Como ya hemos señalado, lo que define a los derechos de grupo como tales es justamente que el titular del derecho no es el individuo sino el grupo como una entidad separada y distinta de cada uno de los individuos que lo componen (Jones 2008). ${ }^{12}$ Para la mayoría de los autores, sin embargo, no cualquier conjunto de individuos podría ser titular de este tipo de derechos, sino que se requiere que el grupo en cuestión pase un cierto umbral de unidad e identidad para reconocerlo como titular (Jones 2008; Galenkamp 1993, pp. 122-123; Wellman 2001, p. 23; McDonald 1991, pp. 218-219). ${ }^{13}$

Miodrag Jovanovi destaca que en la discusión de los derechos de grupos no debe confundirse, sin embargo, a las entidades colectivas -como los grupos étnicos o lingüísticos- con clases de sujetos, como los estudiantes, los trabajadores de la construcción o los funcionarios públicos: "la diferencia más importante es que la existencia de un grupo es mayormente una cuestión de hecho, y no una construcción legal. En otras palabras, los grupos existen 'objetivamente', de forma previa al reconocimiento del Estado" (2012, p. 9). Es decir que, para este autor, la pertenencia al grupo debe estar determinada por motivos sociológicos, prelegales, y no por categorías creadas por el derecho (Jovanovi 2012, p. 127). En igual sentido, Newman propone distinguir entre las colectividades que serían titulares de estos derechos y un conjunto

12 "Un derecho de grupo está definido por su sujeto en lugar de por su objeto" (Jones 2008). Jones señala que este es uno de los pocos puntos en el que existe acuerdo en la doctrina: "Hay poco que no sea controvertido sobre los derechos de grupo pero por lo menos existe bastante acuerdo en su concepto básico: un derecho es un derecho de grupo solo si es un derecho cuyo titular es un grupo en lugar de cada uno de sus miembros por separado" (Jones 1999, p. 354).

13 "Para que un grupo funcione como titular de derecho sus miembros deben verse a sí mismos como normativamente atados los unos a los otros de forma tal que cada uno no actúe simplemente por sí mismo sino que juegue su parte en la consecución de un entendimiento normativo compartido [...] El derecho, en mi opinión, no crea grupos; las entidades colectivas no son ficciones legales" (McDonald 1991, pp. 218-219). 
cualquiera de individuos. Para Newman, a diferencia del mero conjunto de individuos, la identidad de las colectividades se mantiene a través de los cambios en su composición, es decir, es posible identificarla como tal incluso cuando algunos o todos sus miembros cambian; a la vez que los individuos que la integran se identifican como miembros de ellas en una forma no trivial (2004 pp. 128-129).

Si tomamos como característica definitoria de los derechos colectivos la existencia de un grupo que pase cierto umbral de unidad e identidad, se vuelve difícil incluir el derecho a un ambiente sano dentro de esta categoría. Nino, sin embargo, critica en este punto la postura de Raz y propone considerar el derecho a un ambiente sano como un derecho colectivo independiente de la existencia de un grupo de estas características. Esta postura no está exenta de críticas. Jovanovi señala que si relajamos los requerimientos para ser considerados como "grupo" hasta tal punto, muchos derechos que tradicionalmente consideramos como derechos individuales -como el derecho a elegir senadores por la provincia de Catamarca-podrían considerarse también derechos de grupo (en este caso, el derecho dado a todos los habitantes de Catamarca, mayores de 16 años de elegir tres senadores por su provincia). "En casos [...] como el del derecho a votar, la expresión 'derecho de grupo' puede, de hecho, ser usada como sostiene Berry, 'solo en el sentido poco interesante' en el que la mayoría de las normas legales generales clasifican al conjunto de los sujetos a las que están dirigidas" (Jovanovi 2012, pp. 121-122).

\subsection{Problemas relacionados con el ejercicio del derecho}

Si aceptamos la posición de Nino y tomamos como titular del derecho al conjunto de individuos que comparten el interés en la protección del ecosistema (o alguno de sus componentes), todavía nos quedaría por resolver el problema de cómo se ejercería tal derecho (Merrills 2007, p. 670). En efecto, es imposible hablar de derechos de grupo o derechos colectivos sin reconocer la necesidad de que exista algún mecanismo que permita el ejercicio de estos derechos que no responden al modelo de titularidad individual. ${ }^{14}$ Buchanan (1994) señala dos posibilidades: (1) que

14 James W. Nickel identifica seis tipos de actividades que el titular del derecho a menudo necesita llevar a cabo para beneficiarse del derecho reconocido: (i) renunciar, invocar, y usar el derecho; (ii) asumir las responsabilidades que acompañan al derecho; (iii) realizar transacciones sobre el derecho; (iv) interpretar sus alcances; (v) monitorear el cumplimiento y prevenir violaciones; (vi) reclamar el cumplimiento o la compensación en caso de que el derecho sea violado (Nickel 1997, pp. 243-246). 
el grupo como un todo tome decisiones sobre el derecho a través de algún procedimiento mayoritario; ${ }^{15}$ o (2) que algún subconjunto de los miembros del grupo actúe como su agente. ${ }^{16}$ Sin embargo, ninguna de estas opciones está exenta de problemas.

En lo que respecta a la adopción de un procedimiento mayoritario para el ejercicio del derecho, si bien este mecanismo puede ser apropiado para grupos pequeños y relativamente homogéneos en los cuales ya existen mecanismos para la acción colectiva (por ejemplo los grupos indígenas), es difícil concebir su puesta en práctica en el contexto de grupos grandes, altamente heterogéneos y dispersos como los que comparten un mismo ecosistema (Donnelly 2013, pp. 50-51; Jovanovi 2012, p. 115). Los problemas de acción colectiva que se generarían en este último contexto harían muy difícil la adopción de decisiones e implicaría una inversión considerable en la logística y organización del proceso. ${ }^{17} \mathrm{En}$ efecto, para cada caso concreto sería necesario identificar a todos los individuos afectados, organizarlos, establecer un mecanismo consensuado para la toma de decisiones y mantener reuniones periódicas.

Por otra parte, el ejercicio del derecho por medio de un agente tampoco está exento de dificultades. En primer lugar, no es claro cuál sería el mecanismo para la designación del agente que va a representar los intereses del grupo. Si bien en algunos grupos pequeños y homogéneos existen jerarquías y procedimientos establecidos para la elección de representantes, no ocurre lo mismo en los grupos altamente heterogéneos y dispersos que frecuentemente serían titulares del derecho al ambiente sano. ${ }^{18}$ En este último caso, nos enfrentaríamos a los problemas de acción colectiva que mencionamos anteriormente, al menos en lo que respecta a la elección del representante.

David Makinson (1988) señala que en ciertas circunstancias, cuando los órganos de gobierno son elegidos de forma democrática y no

15 Jovanovi pone como ejemplo el derecho a la autodeterminación o el derecho de las minorías lingüísticas a recibir educación en su idioma si alcanzan un mínimo de estudiantes. (Jovanovi 2012, p. 115) Algunos autores sostienen que esta es la única forma en la que podrían ejercerse los derechos colectivos. Véase Dinstein (1976), Miller (1999).

${ }^{16}$ Jovanovi propone el ejemplo de la representación de minorías en los procesos de diseño curriculares. (Jovanovi 2012, p. 115)

${ }^{17} \mathrm{Al}$ mismo tiempo, salvo en grupos muy reducidos, sería difícil o incluso imposible pensar en que todas las decisiones se adopten por consenso. Por tanto, en alguna medida, estaríamos en presencia de una mayoría que actúa como agente del grupo.

${ }^{18}$ En este sentido, Nickel señala que "la falta de una identidad clara frecuentemente dificulta que los grupos tengan un liderazgo autorizado que genuinamente pueda hablar y decidir en nombre del grupo" (Nickel 1997, p. 237). 
discriminatoria, y a intervalos regulares, el Estado podría servir como representante del grupo. Sin embargo, este autor reconoce que esta opción no está exenta de tensiones dado el triple rol que en muchos casos debería desempeñar el Estado: parte sobre la que recaen las obligaciones, representante del titular del derecho y organismo que contiene el aparto judicial que adjudicará la disputa entre ambos. Si bien la tarea no es imposible, requeriría de un aparato estatal con una separación clara de funciones y poderes (Makinson 1988, pp. 77-78). Asimismo, la mayoría de los problemas ambientales cruzan las fronteras territoriales y afectan a los habitantes de más de una unidad política, por lo que en muchos casos no existiría un órgano de gobierno capaz de representar los intereses de todos los afectados.

En cualquier caso, ninguna de las opciones de representación estaría exenta de los problemas de agencia que incluyen la posibilidad de que el agente ejerza el derecho en su propio beneficio o en pos de lo que erróneamente considera es el beneficio del grupo, en lugar de hacerlo en una forma que en la práctica beneficiará a su representado. En este sentido, Buchanan destaca que "si otros tienen que decidir por nosotros si ejercitar, invocar, o renunciar a nuestros derechos, existe la posibilidad de se adopten decisiones paternalistas en nombre de nuestros derechos" (1994 pp. 12-13). Asimismo, la dispersión y falta de cohesión del conjunto de individuos que comparten la titularidad del derecho a un ambiente sano volvería muy difícil para los miembros del grupo "controlar" a su representante, por lo que los problemas de agencia serían mucho más agudos que los que de hecho se encuentran presentes en el ejercicio de otros derechos colectivos.

Frente a estas alternativas, algunos autores proponen una opción más extrema que consiste en permitir que cualquier miembro del grupo ejerza el derecho colectivo en nombre del resto (Handl 1992, p. 48). Este ejercicio individual de derechos colectivos se distancia mucho de la idea de "mayoría" y "representación" propuesta por muchos de los autores que impulsan el reconocimiento de derechos de grupo, ya que no requiere de la existencia de un vínculo entre el grupo y quien ejerce el derecho. De esta forma, se incrementa el riesgo de que el ejercicio del derecho esté desvinculado por completo de los intereses del grupo, ya que no podemos hablar siquiera de un intento del agente por representar los intereses de la comunidad, ni de algún mecanismo de control de esta sobre la conducta de aquel.

En este sentido, McDonald (1991, p. 232) señala que

el riesgo para los intereses de la comunidad se incrementa si los miembros individuales pueden ejercer los derechos por sí mismos sin 
acuerdo previo de la comunidad. Las posibilidades de que ocurra un ejercicio erróneo o incluso malicioso de los derechos se incrementa si el poder de ejercerlos no está sujeto al control del beneficiario. [...] Existe un deslizamiento desde lo nuestro a lo mío que debería ser resistido.

\subsection{Contenido del derecho}

La titularidad colectiva del derecho al ambiente sano impacta directamente en la determinación del nivel de calidad ambiental garantizado. En efecto, si se concibe el derecho a un ambiente sano como un derecho cuyo titular es toda la comunidad, puede entenderse que el nivel de calidad ambiental garantizado por la Constitución es aquel que contribuye a la salud y calidad de vida del conjunto como un todo.

Esta interpretación podría dejar desprotegidos a aquellos individuos más sensibles a determinados problemas ambientales o quienes disfrutan del ambiente de formas más activas que el resto de la población. Por ejemplo, las personas asmáticas o aquellos que sufren alergias o problemas respiratorios generalmente desarrollan síntomas a niveles de contaminación del aire que normalmente serían tolerables para el resto de la población. Del mismo modo, la gente que realiza actividades deportivas en exteriores generalmente se ve especialmente afectada por problemas ambientales que no perjudican a quienes no las realizan.

\section{Conclusiones}

$\mathrm{Al}$ alejarse de la concepción clásica de los derechos de grupo -en la que el titular del derecho es un grupo con características prelegales y con cierto grado de cohesión y organización interna- la titularidad colectiva ya no proporciona una solución a los problemas relacionados con el ejercicio individual del derecho. En efecto, si se acepta que el derecho al ambiente sano como derecho colectivo puede ser ejercido por cualquiera de los miembros del grupo que comparte el interés en la protección del ecosistema, nos enfrentamos necesariamente a los mismos problemas que hemos señalado como argumentos en contra de una titularidad individual.

En segundo lugar, la inclusión del derecho a un ambiente sano dentro de la categoría de los derechos colectivos implica un perjuicio evidente para los individuos que comparten la titularidad del derecho. En efecto, cada miembro individual del conjunto no tiene un control directo sobre el ejercicio del derecho, no tiene siquiera la posibilidad de participar en las decisiones sobre su ejercicio, y puede verse seriamente afectado por 
los resultados de un litigio en el que ni siquiera ha sido reconocido como parte. Asimismo, la calidad ambiental que garantiza el derecho es aquella que vuelve al ambiente sano para el conjunto, y no para cada uno de sus miembros, por lo que los eslabones más débiles de dicho conjunto (niños, ancianos, personas con enfermedades preexistentes) no tendrían un derecho a acceder a una calidad ambiental tal que no impacte en su salud, sino tan solo a un ambiente que sea sano "para el conjunto" como un todo.

Por el contario, si concebimos el derecho a un ambiente sano como un derecho individual, cada uno de los individuos que componen la sociedad tendrá derecho a reclamar la existencia de políticas públicas que aseguren un ambiente sano para él, considerado de forma independiente del resto de los miembros del grupo. Tendrá una "carta de triunfo" que le permitirá vencer las consideraciones de utilidad general o la decisión de la comunidad sobre el nivel óptimo de calidad ambiental. En cambio, al considerarlo un derecho colectivo, este nivel de protección originalmente otorgado al individuo se diluye. El individuo ya no es el titular del derecho, sino que el titular es el conjunto como un todo. El derecho a un ambiente sano pasa a estar definido en función de lo que es sano para la mayoría. El derecho subjetivo sigue cumpliendo un papel como un freno a las políticas públicas que no tengan en cuenta el bienestar del conjunto, pero no necesariamente otorga protección a cada uno de los individuos ni les garantiza una calidad ambiental suficientemente elevada como para que no se afecte su salud.

Esto no implica negar que los derechos a la existencia de bienes públicos tengan características que los diferencian de los derechos que tienen por objeto bienes privados. Tampoco implica sostener que tales derechos encajen sin más en el sistema de derechos fundamentales clásico. Sin embargo, su inclusión en la categoría de los derechos colectivos no solo no captura estas diferencias sino que implica otorgarles a los individuos un nivel de protección que no necesariamente satisface sus necesidades.

\section{Bibliografía}

Badeni, G. (1997), Instituciones del derecho constitucional, Vol. I, Buenos Aires, Ad Hoc.

Bidart Campos, G. J. (2002), Manual de la constitución reformada, Vol. II, Buenos Aires, EDIAR.

Brunnée, J. (1989), “'Common Interest' -Echoes from an Empty Shell?: Some Thoughts on Common Interest and International Environmental Law", Zeitschrift für ausländisches öffentliches Recht und Volkenrecht, 49(4), pp. 791-808. 
Buchanan, A. (1994), "Liberalism and Group Rights", en Coleman, J. L. y Buchanan, A. (eds.), In Harm's Way: Essays in Honor of Joel Feinberg, Nueva York, Cambridge University Press.

Cornes, R. y Sandler, T. (1986), The Theory of Externalities, Public Goods, and Club Goods, Cambridge, Cambridge University Press.

Desai, M. (2003), "Public Goods: A Historical Perspective", en Kaul, I., Conceiçao, P., Le Goulven, K. y Mendoza, R. U. (eds.), Providing Global Public Goods: Managing Globalization, Oxford University Press.

Dinstein, Y. (1976), "Collective Human Rights of Peoples and Minorities", International and Comparative Law Quarterly, 1(25), pp. 102-120.

Donnelly, J. (2013), Universal Human Rights in Theory and Practice, Ithaca, Cornell University Press.

Esaín, J., Minella, G. G. y Jiménez, E. P. (2010), "La cuestión de la tutela ambiental antes y después de la reforma constitucional de 1994", en Gargarella, R. (ed.), Teoría y crítica del derecho constitucional, Vol. II, Buenos Aires, Abeledo-Perrot.

Galenkamp, M. (1991), "Collective Rights: Much Ado about Nothing?: A Review Essay", Netherlands Quarterly on Human Rights, 9, pp. 291-307.

- (1993), Individualism versus Collectivism: The Concept of Collective Rights, Rotterdam, Erasmus Universiteit, Faculteit der Wijsbegeerte.

Green, L. (1991), "Two Views of Collective Rights", Canadian Journal of Law and Jurisprudence, IV(2), pp. 315-328.

Handl, G. (1992), "Human Rights and Protection of the Environment: A Midly 'Revisionist' View", en Trindade, A. A. C. (ed.), Human Rights, Sustainable Development and the Environment, San José de Costa Rica, Instituto Interamericano de Derechos Humanos y Banco Interamericano de Desarrollo.

Hohfeld, W. N. (1913), "Some Fundamental Legal Conceptions as Applied in Judicial Reasoning", Yale Law Journal, 23, pp. 16-59.

Jones, P. (1999), "Group Rights and Group Opression", Journal of Political Philosophy, 7(4), pp. 353-377.

(2008), "Group Rights", en Zalta, E. N. (ed.), The Stanford Encyclopedia of Philosophy.

Jovanovi, M. A. (2012), Collective Rights: A Legal Theory, Nueva York, Cambridge University Press.

Kymlicka, W. (1994), "Individual and Community Rights", en Baker, J. (ed.), Group Rights, Toronto, University of Toronto Press.

Lorenzetti, R. L. (2008), Teoría del derecho ambiental, Buenos Aires, La Ley. 
Makinson, D. (1988), "Rights of Peoples: Point of View of a Logician", en Crawford, J. (ed.), The Rights of Peoples, Oxford, Clarendon Press. McDonald, M. (1991), "Should Communities Have Rights?: Reflections on Liberal Individualism", Canadian Journal of Law and Jurisprudence, 4, p. 217.

Merrills, J. G. (1996), "Environmental Protection and Human Rights: Conceptual Aspects", en Boyle, A. E. y Anderson, M. (eds.), Human Rights Approaches to Environmental Protection, Oxford, Clarendon Press.

(2007), "Environmental Rights", en Bodansky, D., Brunnée, J. y Hey, E. (eds.), The Oxford Handbook of International Environmental Law, Oxford, Oxford University Press.

Miller, S. (1999), "Collective Rights", Public Affairs Quarterly, 13(4), pp. 331-346.

Newman, D. G. (2004), "Collective Interests and Collective Rights", The American Journal of Jurisprudence, 49(1), pp. 127-163.

Nickel, J. W. (1997), "Group Agency and Group Rights", en Shapiro, I. y Kymlicka, W. (eds.), Ethnicity and Group Rights, Nueva York, New York University Press.

Nino, C. S. (1989), Ética y derechos humanos, Buenos Aires, Astrea, $2^{a}$ ed.

— (1992), Fundamentos de derecho constitucional, Buenos Aires, Astrea.

Raz, J. (1984), "Right-Based Moralities", en Waldron, J. (ed.), Theories of Rights, Nueva York, Oxford University Press.

(1986), The Morality of Freedom, Nueva York, Oxford University Press.

Réaume, D. (1988), "Individual, Groups and Rights to Public Goods", University of Toronto Law Journal, 38, pp. 1-27.

Tawil, G. S. (1995), "La cláusula ambiental en la Constitución Nacional", La Ley, 1995-B, 1291.

Waldron, J. (1993), Liberal Rights: Collected Papers 1981-1991, Nueva York, Cambridge University Press.

(2002), "Taking Group Rights Carefully", en Huscroft, G. y Rishworth, P. (eds.), Litigating Rights: Perspectives from Domestic and International Law, Portland, Hart Publishing.

Wellman, C. (2001), "Alternatives for a Theory of Group Rights", en Sistare, C., May, L. y Francis, L. (eds.), Groups and Group Rights, Lawrence, University Press of Kansas. 